\title{
REVISÃO: INFLUÊNCIA DO TRATAMENTO TÉRMICO DO LEITE DESTINADO À FABRICAÇÃO DE QUEIJO
}

\author{
RENATA TORREZAN*
}

\begin{abstract}
Apresenta revisão de literatura sobre os tipos de tratamento térmico aplicados ao leite e seus efeitos tecnológicos na elaboração de queijos. Discute aspectos legais, sugerindo ajuste na legislação vigente.
\end{abstract}

\section{INTRODUÇÃO}

O tratamento térmico do leite afeta o $\mathrm{pH}$, a matéria seca total, a microbiota, a consistência, a acidez titulável, nitrogênio não protéico e nitrogênio solúvel, enquanto outros parâmetros permanecem inalterados com o aquecimento (58). BACHMANN et al. (5) afirmam que queijos feitos com leite cru tendem a desenvolver sabor mais forte e específico e maturam mais rapidamente do que os elaborados a partir de leite pasteurizado.

$\mathrm{Na}$ atualidade, muitos artigos têm discutido a importância da adoção do tratamento térmico para queijos, enfocando sua obrigatoriedade em alguns países industrializados, a prevenção de riscos à saúde pública, bem como vantagens e desvantagens tecnológicas $(4,5,7,13,30,43,58)$.

A fabricação de queijo é um processo que pode durar meses, da coleta do leite ao final da maturação. Entretanto, os principais fatores que determinam suas características finais são definidos no espaço de poucas horas, começando com a chegada do leite a fábrica até sua prensagem nas formas. Este período é crucial porque os tratamentos dispensados ao leite e à coalhada determinarão o tipo de queijo a ser elaborado, suas características e seu grau de qualidade (22). Na fase de preparo do leite, um dos tratamentos térmicos mais utilizados é a pasteurização.

\footnotetext{
MSc em Tecnologia de Alimentos, Técnico Especializado da Empresa Brasileira de Pesquisa Agropecuária (EMBRAPA), Centro Nacional de Pesquisa e Tecnologia Agroindustrial de Alimentos (CNPTAA), Guaratiba, Rio de Janeiro (RJ)
} 
A maior parte das indústrias de queijos utiliza leite pasteurizado, exceto para alguns tipos de queijos tradicionais que exigem leite cru. Em países em desenvolvimento, nos quais a qualidade microbiológica do leite é, em geral, precária, a pasteurização torna-se indispensável, tanto sob o ponto de vista tecnológico como de saúde pública.

A qualidade do leite pasteurizado está intimamente ligada à qualidade da matéria-prima (leite cru). É impossível somente por meio da pasteurização transformar o leite de qualidade inferior em leite de boa qualidade. O sistema de pasteurização não corrige os defeitos provenientes de más condições de higiene durante e após a ordenha (12). A pasteurização deve ser realizada sob controle e, após este tratamento, devem ser tomados todos os cuidados necessários para evitar a contaminação do produto.

A pasteurização do leite para queijos não é totalmente aceita como o é para leite de consumo. O leite destinado à industrialização de queijos é sensivel à influência da temperatura, devido a certas modificações que podem afetar tecnologicamente a elaboração dos queijos.

WILSTER (56) cita as seguintes vantagens em se adotar a pasteurização do leite para queijo: melhoria do sabor após a cura, eliminação das bactérias patogênicas, destruição das bactérias produtoras de gás, maior facilidade no controle do processamento com relação à produção de ácido, maior uniformidade e ligeiro aumento no rendimento. Como desvantagens menciona pequeno aumento dos custos de processamento, maturação mais lenta e menor desenvolvimento do aroma e sabor nos queijos.

As pesquisas sobre pasteurização do leite destinado à fabricação de queijos começaram no final do século 19, mas sua aplicação comercial foi vagarosa, com exceção da Nova Zelândia, que já a adotava quase que totalmente na década de 20 (32).

A legislação brasileira proibe a fabricação de queijo com leite cru, à exceção daqueles maturados por, no mínimo, 60 dias. Não há diferenciação entre a pasteurização de leite de consumo com o destinado à fabricação de queijos, seja em relação a temperatura de aquecimento, tempo de residência ou temperatura de resfriamento (8).

\section{TIPOS DE TRATAMENTOS TÉRMICOS UTILIZADOS}

\subsection{PASTEURIZAÇÃO}

A Legislação Brasileira (8) define a pasteurização como "emprego conveniente de calor, com o fim de destruir totalmente a flora microbiana patogênica, sem alteração sensível da constituição física e do equilíbrio químico do leite, sem prejuizo dos seus elementos bioquímicos, assim 
como de suas propriedades organolépticas normais". A legislação em vigor prevê os processos de pasteurização lenta e de curta duração. A pasteurização lenta consiste no aquecimento do leite a $62-65^{\circ} \mathrm{C}$ por 30 minutos, mantendo-se o leite em grande volume, sob agitação mecânica lenta, em aparelhagem própria. A pasteurização de curta duração ou High Temperature Short Time (HTST) consiste no aquecimento do leite em camada laminar a $72-75^{\circ} \mathrm{C}$ por $15-20$ segundos, em aparelhagem própria, convenientemente instalada e em perfeito funcionamento, provida de dispositivo de controle automático, como termo regulador, registradores de temperatura e outros que venham a ser considerados necessários, para o controle sanitário da operação. A pasteurização lenta pode ser feita no tanque de elaboração ou em separado, de acordo com a conveniência e produção da queijaria. Geralmente, estes tanques dispõem de camisa de vapor. Como é necessário manter a temperatura adequada $\left(62-65^{\circ} \mathrm{C}\right) \mathrm{em}$ todo o tanque, agitação lenta e contínua é requerida. Deve-se observar o tempo de tratamento (30 minutos), fazendo-se posteriormente o resfriamento. Se o aquecimento for realizado no tanque de elaboração, pode-se resfriar até cerca de $34{ }^{\circ} \mathrm{C}$ e iniciar imediatamente as demais etapas do processo. No caso do leite ser submetido à estocagem, anterior ao processamento, o mesmo deve ser resfriado a $10{ }^{\circ} \mathrm{C}$ (ou mais frio), sendo mantido sob temperatura de refrigeração e em condições higiênicas, até a sua utilização. Nos sistemas contínuos, como no caso do HTST, o processo pode ser realizado em trocadores de calor de placas, feitas de aço inox, superpostas verticalmente em moldura rígida. Estas placas são agrupadas em seções de aquecimento e regeneração.

Segundo AJZENTAL (3) as etapas pelas quais o leite passa num trocador de calor de placas se inicia no tanque de equilíbrio, que mantém o nível constante do leite, através de uma bóia. Deste tanque, o leite é bombeado em fluxo constante à seção de regeneração, sendo pré-aquecido pelo leite já pasteurizado que sai do retardador. O leite já pasteurizado também se beneficia do regenerador, pois é pré-resfriado, economizando energia. 0 leite pré-aquecido passa pelo filtro ou clarificador e depois, pela seção de aquecimento, sendo aquecido até atingir a temperatura do binômio, préestipulada (geralmente $72{ }^{\circ} \mathrm{C}$ por 15 segundos); circula posteriormente pela tubulação do retardador pelo tempo necessário, retornando ao regenerador. O resfriamento do leite é feito no trocador de calor, sendo o mesmo mantido em tanques isotérmicos de estocagem até a sua utilização. O meio de aquecimento é normalmente água quente, que circula através da seção de aquecimento do trocador de calor de placas numa taxa várias vezes superior ao fluxo do leite. O leite pode ser aquecido nas temperaturas desejadas com pequenas diferenças de temperatura $\left(1^{\circ} \mathrm{C}\right)$ entre este e o meio de aquecimento, fator importante em se tratando de produto termolábil. A temperatura de aquecimento e de manutenção é registrada continuamente em termógrafo. Caso o binômio de tempotemperatura não seja atingido no retardador, uma válvula reversora de fluxo automaticamente devolve o leite ao tanque de equilibrio. 
A maioria das fábricas de queijos dispõe de equipamentos modernos para a pasteurização do leite (como o sistema HTST), mas, nas pequenas, sobretudo naquelas localizadas na região sul de Minas Gerais, ainda se usa o sistema conhecido como ejetor de vapor (57).

O ejetor de vapor é considerado o primeiro sistema de pasteurização de leite destinado à industrialização de queijos no Brasil. Baseia-se no princípio de condensação do vapor diretamente no leite, permitindo aquecimento rápido em fluxo contínuo. $O$ equipamento é de custo relativamente baixo e de fácil funcionamento (52). O ejetor consiste essencialmente num bico que introduz jato de vapor no seio da câmara de expansão. O leite a aquecer é, assim, aspirado e aquecido pelo jato de vapor na câmara de mistura. Em seguida, a mistura leite+vapor é conduzida por tubulação de comprimento variado, dependendo do qual, a temperatura é mantida por tempo determinado, antes do leite ser resfriado em resfriador de cascata. A condensação do vapor provoca incorporação de água, que leva a diluição do leite, podendo variar de 7 a $11 \%$ em função da pressão de vapor (entre 2,1 e 6,3 $\mathrm{kgf} / \mathrm{cm}^{2}$ ) e da temperatura inicial do leite cru ( entre 10 e $30^{\circ} \mathrm{C}$ ). Queijos fabricados com leite tratado pelo ejetor de vapor apresentam coloração mais clara, coalhada mais macia, maior rendimento na fabricação e menor perda de gordura no soro (21). VENTURA \& RUSIG (53) testaram este sistema nas faixas de tempo e temperatura fixadas pela legislação e comprovaram que os tratamentos estudados atendem suas exigências. Foi observado que na fabricação de queijo tipo Prato, utilizando leite tratado pelo ejetor de vapor, o rendimento é maior, sem que ocorra variação sensivel de composição. Além disso suas características sensoriais são superiores à dos tratados em trocador de calor de placas (54).

\subsection{TERMIZAÇÃO}

A termização é o tratamento térmico controlado por $5-20 \mathrm{~s}$, utilizando vapor direto. É usado para vários tipos de queijos e indicado como ideal para os tipos Prato e afins, além de todos os tipos de queijos macios, como os europeus (Itálico, Roquefort, Gouda, Port-Salut e outros) (52).

A termização é muito utilizada na Holanda como pré-tratamento do leite cru, que será estocado em temperaturas de refrigeração. A termização irá destruir a maioria dos psicrotróficos e prevenir a ação enzimática em temperatura de refrigeração. A termização reduz também a contagem aeróbica em placa e permite a estocagem do leite por, pelo menos, 4 dias a $4{ }^{\circ} \mathrm{C}$, sem a ocorrência de aumento excessivo no número de microrganismos presentes. A termização não apresenta efeito na desnaturação das proteínas do soro e estabilidade do complexo caseínico, permanecendo o $\mathrm{pH}$ inalterado durante a estocagem (14). 
ZALAZAR et al. (59) analisaram a qualidade de queijo "Pategras" elaborado a partir de leite aquecido a $65^{\circ} \mathrm{C}$ por 4 minutos e refrigerado a $5{ }^{\circ} \mathrm{C}$ por 96 horas. Comprovaram que este tratamento destruiu a microbiota psicrotrófica e as bactérias acidificantes e que a qualidade final dos queijos foi superior até mesmo quando utilizaram leite com alta contagem microbiana inicial.

SWART et al. (49) estudaram os efeitos da termização do leite (antes da estocagem) sobre a contagem de psicrotróficos, gordura, proteína e sólidos totais durante o processamento de queijo Cheddar. Não foram encontradas diferenças significativas em relação aos sólidos totais, gordura e proteína. Porém, com relação a contagem de psicrotróficos, houve redução de $85 \%$ quando utilizaram termização a $65^{\circ} \mathrm{C} / 15 \mathrm{~s}$, prolongando a estocagem a $5^{\circ} \mathrm{C}$, por pelo menos 3 dias. As bactérias psicrotróficas mostraram ligeira ação proteolítica, com reflexos no rendimento do queijo, e não exibiram ação lipolítica, conforme demonstrado pelas características sensoriais.

HESKESTAD (27) relatou o efeito da termização $\left(67^{\circ} \mathrm{C} / 15 \mathrm{~s}\right)$ sobre a qualidade do queijo norueguês. $O$ leite termizado foi estocado a $4-5{ }^{\circ} \mathrm{C}$ por 3 dias antes de iniciar o preparo dos queijos. A termização reduziu consideravelmente a contagem aeróbica em placa, bactérias psicrotróficas e coliformes, aumentando a contagem de bactérias esporuladas. 0 queijo norueguês elaborado com leite termizado obteve melhor qualidade e sabor do que o elaborado com leite cru, após dez semanas de estocagem. Após 3 meses de estocagem, não houve diferença significativa entre estes produtos. O número de olhaduras formadas, a consistência e a textura foram similares para ambos os produtos.

HANDLAND (25) investigou os fatores que influenciam a termização do leite $\left(68^{\circ} \mathrm{C} / 15 \mathrm{~s}\right)$ e a posterior estocagem $\left(1-3\right.$ dias a $\left.4-6^{\circ} \mathrm{C}\right)$. A termização aumentou a contagem das bactérias lácticas e propiônicas, enquanto destruiu os psicrotróficos e afetou ligeiramente as proteínas. A termização afeta a coagulação tornando-a mais lenta. É possivel manter a temperatura de estocagem a $8-10^{\circ} \mathrm{C}$, reduzindo $0 \mathrm{pH}$ em $0,1-0,2$. Este tipo de estocagem produz ligeira proteólise e proporciona melhor substrato para as bactérias, afetando positivamente a qualidade dos queijos.

HONER (29) estudou o emprego de tratamento térmico mais brando (termização) do leite $\left(63-67^{\circ} \mathrm{C} / 16 \mathrm{~s}\right)$ e a adição de culturas lácticas controladas ao leite cru (antes do aquecimento) na produção de queijo Cheddar. Verificou melhoria no sabor e textura, principalmente nos queijos com baixo teor de gordura. 


\subsection{PASTEURIZAÇÃO DUPLA}

A pasteurização dupla consiste basicamente no uso combinado de dois processos: a termização $\left(63-67^{\circ} \mathrm{C} / 20-30 s\right)$ e a pasteurização (71-74 $\left.{ }^{\circ} \mathrm{C} / 20-30 \mathrm{~s}\right)$.

KARLIKANOVA \& DUROVA (35) relatam o uso da pasteurização dupla na manufatura de queijos tradicionais russos, como: Rossiiskii, Dutch Brick, Kostroma e Poshekhonskii com melhoria da qualidade global em relação aos queijos elaborados com leite pasteurizado. $\mathrm{O}$ tratamento utilizado foi a termização $\left(65^{\circ} \mathrm{C} / 20-25 \mathrm{~s}\right)$, seguido de estocagem a $8-10{ }^{\circ} \mathrm{C}$ por $48-72$ horas (sem afetar as características básicas do leite) e posterior pasteurização pelo processo HTST $\left(71-72^{\circ} \mathrm{C} / 20-25 s\right)$. RAMAZANOV (47) também menciona o uso da termização $\left(63-65^{\circ} \mathrm{C} / 30 \mathrm{~s}\right)$, estocagem por $72 \mathrm{~h}$ e pasteurização $\left(71-74^{\circ} \mathrm{C} / 25 \mathrm{~s}\right.$ ) para melhorar a qualidade de queijos russos ("pickled cheeses").

KWON et al (38) estudou alguns fatores que afetam o rendimento do queijo. A pasteurização dupla aumentou o rendimento em cerca de $3 \% \mathrm{em}$ relação a pasteurização simples.

\section{EFEITOS DO TRATAMENTO TÉRMICO DO LEITE}

\subsection{CARGA MICROBIANA}

A COMISSION DEL CODEX ALIMENTARIUS (15), da Organização Mundial de Saúde, define como pasteurização o processo aplicado ao leite, visando reduzir ao mínimo os possíveis perigos para a saúde, provenientes dos microrganismos patogênicos associados ao leite. Tal processo consiste em tratamento térmico que provoque alterações químicas, físicas, bioquímicas e sensoriais mínimas no produto.

Inicialmente, considerou-se como padrão de resistência térmica o Micobacterium tuberculosis, microrganismo mais resistente entre os patógenos $\left(71,1^{\circ} \mathrm{C} / 15 \mathrm{~s}\right)$ associados ao leite. Atualmente, o controle do aquecimento é baseado na sobrevivência de Coxiela burnetti, agente causador da febre $Q$ no homem. A destruição deste microrganismo requer tratamento de $71,7^{\circ} \mathrm{C} / 15 \mathrm{~s}(12)$.

A prova de fosfatase utilizada para controle do tratamento térmico é muito eficaz, pois fosfatase negativa evidencia que a maioria dos microrganismos patogênicos foram significativamente destruídos, assegurando que não houve mistura com leite cru. Esta enzima é inativada a $62,8^{\circ} \mathrm{C} / 30$ minutos. A prova para atividade de peroxidase deve ser positiva para comprovar que o leite não foi exageradamente aquecido. 
A Tabela 1 lista patógenos e viroses que podem ocorrer em queijos. Os microrganismos considerados de baixo risco referem-se àqueles até 0 momento não detectados em queijos, mas que podem ocorrer no leite ou, em alguns casos, seu controle é efetivo e bem conhecido.

\section{TABELA 1 - ALGUNS PATÓGENOS, ANO REGISTRADO DE INCIDÊNCIA, DOENÇA TRANSMITIDA E OUTRAS OBSERVAÇÕES, VEICULADOS VIA LEITE CRU OU PASTEURIZADO INADEQUADAMENTE}

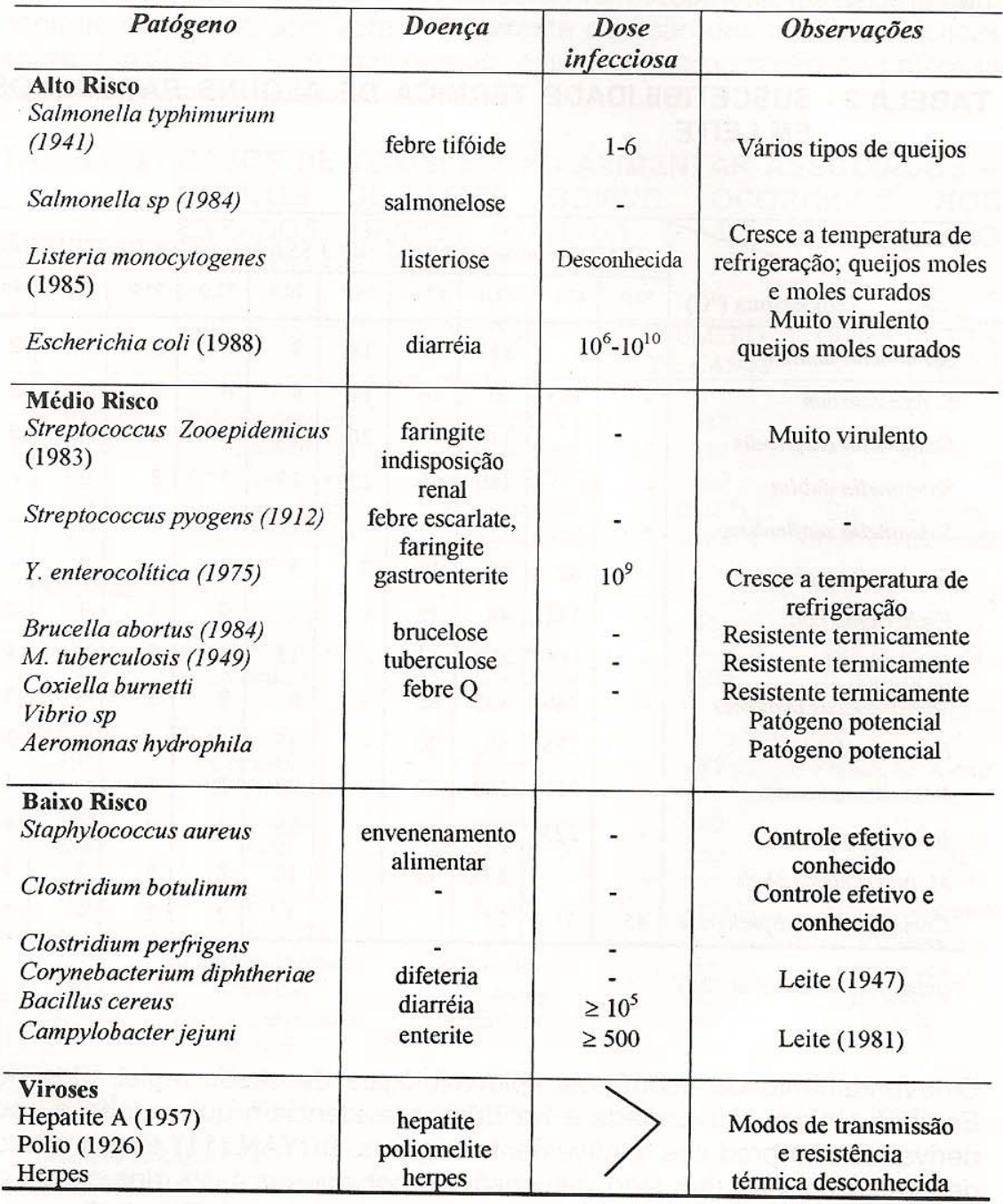

Fonte: D'AOUST (16); JOHNSON et al. (33); EYLES (19). 
A Tabela 2 apresenta a suscetibilidade térmica de alguns microrganismos patogênicos. Observa-se, pelos dados desta tabela, que os binômios tempo-temperatura normalmente utilizados para a pasteurização (62-65 ${ }^{\circ} \mathrm{C} / 30 \mathrm{~min}$ ou $72-75^{\circ} \mathrm{C} / 15-20 \mathrm{~s}$ ) atendem à necessidade de eliminação dos mesmos.

AJZENTAL (2) avaliou a influência da carga bacteriana inicial no mecanismo de inativação de leite (HTST), em 41 amostras, comprovando que o binômio tempo-temperatura utilizado no Brasil para este processo não precisa ser alterado.

TABELA 2 - SUSCETIBILIDADE TÉRMICA DE ALGUNS PATÓGENOS EM LEITE

\begin{tabular}{l|l|l|l|l|l|l|l|l|l|l}
\hline Patógeno & \multicolumn{10}{c}{ TEMPO EM SEGUNDOS NECESSÁRIO PARA DESTRUIC̃O } \\
\cline { 2 - 10 } \multicolumn{1}{c}{ Temperatura $\left({ }^{\circ} \mathrm{C}\right)$} & 50,0 & 60,0 & 62,0 & 65,0 & 68,0 & 70,0 & 72,0 & 75,0 & 78,0 & 80,0 \\
\hline Salmonella anatum & - & - & 85 & 43 & 18 & 9 & 6 & 5 & - & 2 \\
S. typhimurium & - & 135 & 90 & 40 & 14 & 8 & 6 & 4 & - & 2 \\
Salmonella enteritidis & - & - & 140 & 70 & 26 & 13 & 8 & 5 & - & 2 \\
Salmonella dublin & - & - & 140 & 65 & 25 & 13 & 7 & 3 & 2 & - \\
Salmonella senftenberg & - & - & - & - & - & $\sim 20$ & - & - & - & - \\
Salmonella typhosa & - & 82 & 42 & 19 & 7 & 5 & 3 & - & 2 & - \\
Escherichia coli & - & 125 & 48 & 18 & - & - & 7 & 4 & 3 & 2 \\
Staphylococcus aureus & - & 1330 & 690 & 63 & - & 15 & 11 & 7 & 5 & 4 \\
Streptococcus pyogenes & - & 180 & 135 & 65 & - & 8 & 7 & 5 & 3 & 2 \\
Brucella abortus & - & 175 & 55 & 20 & - & 15 & 12 & 9 & - & 3 \\
Brucella melitensis & - & 210 & 100 & 32 & - & 22 & 20 & 12 & - & 4 \\
Brucella suis & - & 225 & 120 & 56 & - & 25 & 17 & 9 & 6 & 4 \\
M. tuberculosis bovis & - & - & 105 & 17 & - & 10 & 8 & 8 & 5 & 3 \\
Corybacterium diphtheriae & 45 & 31 & 21 & - & - & 3 & 2 & 2 & - & 2 \\
\hline
\end{tabular}

Fonte: JOHNSON et al. (33).

O levantamento da ocorrência epidemiológica de casos registrados nos Estados Unidos, no Canadá e na Europa evidenciam que o leite e seus derivados são produtos relativamente seguros. BRYAN (11) afirma que os derivados de leite têm sido responsáveis por apenas $1-3 \%$ dos casos de toxinfecção alimentar sucedidos nos Estados Unidos. A Tabela 3 mostra alguns casos ocorridos nos Estados Unidos, Canadá e Europa. Os casos 
mais graves ocorreram nos Estados Unidos com o queijo mole de preparação caseira em que foram relatados casos de morte. Nos EUA e Canadá, a maior causa de contaminação é a recontaminação do leite após a pasteurização e, na Europa, é o uso de leite cru. Nos queijos italianos duros (Parmesão, Romano e Provolone) não foi detectada a presença de patógenos. Os queijos com maior incidência de patógenos foram o Brie e o Camembert (34).

Com o tratamento térmico há também a eliminação da microbiota natural do leite, daí a necessidade de se adicionar fermento, tornando mais fácil o controle da acidez, pois esta é decorrente da ação das bactérias lácticas sobre a lactose do leite, melhorando, assim, a padronização do processo de manufatura dos queijos.

TABELA 3 - CASOS DE TOXINFECÇÃO ALIMENTAR ASSOCIADOS A QUEIJOS DE LEITE BOVINO, OCORRIDOS NOS ESTADOS UNIDOS, CANADÁ E NA EUROPA, NO PERIODO DE 1971-1987

\begin{tabular}{|c|c|c|c|c|}
\hline ANO & TIPO DE QUEIJO & PATÓGENO & $\begin{array}{l}\text { NÚMERO } \\
\text { DE CASOS }\end{array}$ & OBSERVAÇÕES \\
\hline \multicolumn{5}{|l|}{ - EUA } \\
\hline 1971 & Brie/Camembert & E. coli (EIEC) & 387 & - \\
\hline 1976 & Cheddar & S. heidelberg & 339 & - \\
\hline 1983 & Brie/Camembert & E.coli (ETEC/ST) & 169 & - \\
\hline 1983 & Mexicano-caseiro & S. zooepidermicus & $16(2 *)$ & Uso de leite cru \\
\hline 1985 & $\begin{array}{c}\text { Mexicano-queijo } \\
\text { mole }\end{array}$ & L. monocytogenes & $181\left(65^{*}\right)$ & Meio contaminado \\
\hline \multicolumn{5}{|l|}{ - Canadá } \\
\hline 1977 & Emmental & S. aureus & 15 & - \\
\hline 1982 & Cheddar e outros & Salmonella & - & Uso de leite cru \\
\hline 1984 & Cheddar & S. typhimurium & 1500 & $\begin{array}{l}\text { Falhas na } \\
\text { pasteurização }\end{array}$ \\
\hline \multicolumn{5}{|l|}{ - Europa } \\
\hline 1971 & Camembert & E. coli & 387 & França, EUA-exp \\
\hline 1974 & queijo mole & C. botulinum & 77 & Franca, Suica \\
\hline 1981 & Mussarela & S. typhimurium & 100 & Itália \\
\hline 1982 & Brie & $\begin{array}{c}\text { Bacillus sp. } / S . \\
\text { sonnei }\end{array}$ & $>50$ & Escandinávia \\
\hline 1983 & Brie & E.coli & $>350$ & $\begin{array}{c}\text { França, Suiça e } \\
\text { Holanda }\end{array}$ \\
\hline 1983 & queijo da fazenda & Salmonella sp. & 35 & Finlândia \\
\hline 1983 & Cheddar & S. aureus & 02 & Inglaterra \\
\hline $1983-84$ & $\begin{array}{l}\text { queijo caseiro não } \\
\text { curado }\end{array}$ & Brucella sp. & 23 & Grécia \\
\hline 1985 & Vacherin & Salmonella sp. & 215 & Suiça, França \\
\hline $1983-87$ & Vacherin & L. monocytogenes & $>31$ & Suiça \\
\hline
\end{tabular}

* Número de casos fatais.

Fonte: D'AOUST (16); JOHNSON et al. (33). 


\subsection{PROTEÍNAS DO LEITE}

O tratamento térmico do leite, ainda que moderado, provoca alterações na estrutura e nas propriedades das proteínas do soro e da caseína, tais como desnaturação, coagulação, interação entre proteínas e sedimentação, entre outras. As proteínas do soro estão sujeitas a maiores variações do que o complexo caseína, pois este apresenta termoestabilidade. Os efeitos térmicos na caseína ocorrem seletivamente sobre determinadas frações da micela, sendo que a $\beta$-caseína se revela mais estável que a fração $\alpha$. No interior da fração $\alpha$, a א-caseína apresenta grande sensibilidade, encontrando-se protegida pela fração $\alpha$ s (51).

A pasteurização do leite diminui seu teor de proteínas solúveis, ocorrendo interação entre as proteínas do soro (principalmente $\beta$-lactoglobulina) e a $\kappa$ -caseína. Há precipitação dos agregados e complexos formados com a caseína, durante a coagulação do leite por coalho. O complexo formado entre a $\beta$-lactoglobulina e a $\kappa$-caseína dificulta a ação da renina nesta fração da caseína. Em conseqüência, a floculação inicial do leite é ligeiramente retardada (aumento de $20 \%$ no tempo de floculação em relação ao leite cru). O aumento do teor de proteínas solúveis retidas no queijo pode elevar ligeiramente o rendimento da fabricação e provocar maior retenção da água no queijo, levando a formação de coalhada mais branda e grãos com maior dificuldade para dessorar. O tempo de coagulação do leite cresce dez vezes, se o mesmo for aquecido a $92{ }^{\circ} \mathrm{C}$ por 15 segundos (22).

BANKS et al (7) estudando o efeito do tratamento térmico sobre as proteínas do soro, sob determinadas condições de $\mathrm{pH}(6,5$ - 8,7), verificaram que as propriedades sensoriais e funcionais do queijo Cheddar podem ser melhoradas pelo ajuste do $\mathrm{pH}$ antes do tratamento térmico.

USTUNOL \& BROWN (50) citados por FOX \& MORRISEY (20) relataram que o aquecimento do leite a temperaturas acima de $75^{\circ} \mathrm{C}$ por 30 minutos inibe a ação enzimática. Por isso recomendam que o leite para queijo não seja aquecido acima das temperaturas requeridas pelo processo de pasteurização. MORR (40) afirma que a pasteurização $\left(72^{\circ} \mathrm{C} / 16 \mathrm{~s}\right)$ não tem efeito sobre as enzimas presentes no leite e não afeta significativamente a solubilidade das proteínas do soro.

Como já mencionado anteriormente a $\beta$-lactoglobulina é susceptível à desnaturação e representa $55 \%$ da fração proteíca do soro (51). No caso de utilização do soro do leite, deve-se adotar o tratamento térmico que quase não afete a desnaturação proteíca para manter as propriedades funcionais adequadas do soro. 


\subsection{CLORETO DE CÁLCIO}

No processo de coagulação do leite, a presença de cálcio solúvel, sob a forma ionizada, é essencial. O cálcio estabelece uma ponte entre as micelas de paracaseína, formando uma rede - a coalhada. As caseínas $\alpha$ e $\beta$ são sensíveis ao cálcio e se insolubilizam (coagulam) em sua presença. No leite, a к-caseína as envolve como colóide protetor. A renina hidrolisa a к-caseína e expõe as outras frações ao cálcio solúvel na fase aquosa, provocando a coagulação do leite. $O$ coalho predispõe o leite à coagulação, mas, para que esta ocorra, deve ser complementada pela ação do cálcio (22).

A concentração de cálcio solúvel é fortemente afetada pela temperatura, isto é, há deslocamento da fase solúvel (aquosa) para a fase protéica. Esta fixação de cálcio conduz à precipitação de fosfato tricálcio, quando o teor de proteínas do leite é inferior a $8 \%$ (como no leite de vaca). A pouca solubilidade do fosfato tricálcio em temperatura elevada é responsável pelo deslocamento do equilíbrio do cálcio solúvel para a fase coloidal. Mediante a formação de fosfato de cálcio coloidal eleva-se a concentração de íons hidrogênio, resultando em abaixamento do $\mathrm{pH}(10)$.

Como na pasteurização do leite uma parte do cálcio é insolubilizada, adiciona-se cálcio complementar ao leite, sob a forma de cloreto de cálcio, quando da fabricação de queijo. Após a pasteurização, o leite tende a coagular-se mais lentamente e formar coalhada mais branda. Basta a adição de $6 \mathrm{~g}$ de $\mathrm{CaCl}_{2} / 100$ litros de leite pasteurizado $\left(72{ }^{\circ} \mathrm{C} / 20 \mathrm{~s}\right)$ para que este reduza o tempo de coagulação para o mesmo tempo requerido pelo leite cru. $\mathrm{Na}$ prática, são adicionados $20 \mathrm{~g}$ de $\mathrm{CaCl}_{2}$ para cada 100 litros de leite, na forma de solução aquosa a $50 \%$, pasteurizada e resfriada. A adição de cloreto de cálcio reduz o tempo de coagulação, aumenta a firmeza da coalhada e melhora a expulsão do soro da coalhada, entre outros benefícios. Porém, não se pode abusar da quantidade de cloreto de cálcio, que está limitada a $40 \mathrm{~g} / 100 \mathrm{~L}$ de leite, para evitar o aparecimento de gosto amargo no queijo (22).

\subsection{SABOR}

Alguns autores têm relatado que o sabor dos queijos feitos a partir do leite pasteurizado são desenvolvidos mais lentamente durante a cura e são menos intensos $(6,36,37)$.

Outros autores têm demonstrado que os queijos feitos a partir do leite pasteurizado apresentam melhor qualidade global e poucos defeitos de sabor e aroma em relação ao feito com leite cru $(1,23)$. A termização na fazenda, como já relatada anteriormente, proporciona o controle de 
microrganismos psicrotróficos, que podem ocorrer no leite estocado a frio, causando sabores estranhos e diminuindo a qualidade dos queijos.

O grande desafio da tecnologia é a formulação de produtos seguros microbiologicamente, com melhores características de sabor e aroma. GLAESER (24) acredita que os desenvolvimentos futuros, baseados na relação entre as propriedades microbiológicas e bioquímicas, permitirão a obtenção de queijos feitos a partir de leite devidamente pasteurizado com características sensoriais similares aos produzidos com leite cru.

Alguns tipos de queijos são afetados adversamente pelo tratamento térmico, como é o caso do queijo suiço e dos queijos italianos duros (Romano, Parmesão e Asiago), elaborados tradicionalmente com leite cru. A lipase tem ação particular nestes tipos de produtos, conferindo-lhes sabor característico (picante). Pasteurização a $72{ }^{\circ} \mathrm{C} / 15 \mathrm{~s}$ reduz mais de $90 \%$ da atividade da lipase, enquanto que o tratamento a $60-67{ }^{\circ} \mathrm{C} / 15 \mathrm{~s}$ contribuiu para a perda de mais de $60 \%$ da atividade desta enzima (33).

A pasteurização do leite afeta a taxa de retenção do coalho pela coalhada e a formação do gosto amargo. $\mathrm{O}$ aquecimento do leite a temperaturas elevadas provoca modificações estruturais na caseína e precipita parte das chamadas proteinas solúveis, aumentando a capacidade de retenção de água pela coalhada. Além disso, enzimas proteolíticas são inativadas e a maior parte da microbiota natural do leite é eliminada. Estes fatores somados ao fato de se observar maior retenção no coalho, quando se utiliza leite pasteurizado, levaram a conclusão de que, quanto maior a intensidade do tratamento térmico maior a probabilidade de aparecimento de gosto amargo no produto (22).

FURTADO (22) cita dois trabalhos que comprovam a relação entre gosto amargo, retenção de coalho e aquecimento do leite. No primeiro, o queijo fabricado com leite pasteurizado a $73{ }^{\circ} \mathrm{C} / 15 \mathrm{~s}$ revelou duas vezes mais coalho do que outro elaborado com leite cru ou aquecido a $65^{\circ} \mathrm{C} / 15 \mathrm{~s}$. No segundo foram comparados queijos Gouda fabricados com leite pasteurizado a $74{ }^{\circ} \mathrm{C} / 10 \mathrm{~s}$ e a $82^{\circ} \mathrm{C} / 10$ s. Este último apresentou $21 \%$ a mais de retenção de coalho e a intensidade de gosto amargo foi quase três vezes superior à observada no queijo feito com leite menos aquecido.

\subsection{RENDIMENTO}

Quanto mais severo o tratamento térmico, maior o rendimento da fabricação, pois há menor dessoragem. Entretanto isto só é aconselhável para certos tipos de queijos, como o Petit Suisse. Os queijos duros e semiduros apresentarão sérios problemas se houver superaquecimento do leite (22). 
DZUREC \& ZALL (17) afirmaram que, para o queijo Cottage, o uso da pasteurização $\left(74^{\circ} \mathrm{C} / 10 \mathrm{~s}\right)$ e estocagem a $3^{\circ} \mathrm{C}$ por sete dias, aumentou o rendimento de fabricação, em relação à pasteurização mais usual $\left(72^{\circ} \mathrm{C} / 15 \mathrm{~s}\right)$.

JENSEN (31) comparou o uso dos tratamentos térmicos a 95 e $72{ }^{\circ} \mathrm{C}$, ambos por $15 \mathrm{~s}$, em queijos dinamarqueses, obtendo rendimento cerca de $5 \%$ maior para os queijos submetidos a temperatura mais elevada. A composição e a qualidade sensorial dos produtos foram semelhantes após oito semanas de maturação.

MARSHALL (39) obteve rendimentos significativamente maiores (4-5\%) no queijo Cheshire, utilizando tratamento a $97^{\circ} \mathrm{C} / 15 \mathrm{~s}$. Verificou também a desnaturação de cerca de $30 \%$ das proteínas do soro.

\subsection{XANTINA OXIDASE}

A enzima xantina oxidase está normalmente presente no leite, tanto na forma livre como ligada à fração lipídica do leite. Esta enzima também apresenta habilidade de catalisar a oxidação de alguns compostos não específicos (43). Segundo FURTADO (22), esta enzima provoca a redução de nitrato a nitrito. $O$ nitrito, e não o nitrato, apresenta ação preventiva contra os microrganismos butíricos, promotores da fermentação butírica que prejudica o sabor e odor dos queijos. A pasteurização do leite em temperaturas muito elevadas, capazes de destruir a enzima xantina oxidase, pode prejudicar a ação dos nitritos (via nitratos). No leite aquecido a $85^{\circ} \mathrm{C} / 10$ s a xantina oxidase é destruída. Nestes casos, normalmente se adiciona $0,05 \%$ de nitrato de sódio, o que porém não impede a fermentação butírica. Quando o aquecimento é feito a $80^{\circ} \mathrm{C} / 10$ s a xantina oxidase permanece intacta, sendo portanto, capaz de reduzir o nitrato à nitrito, o qual desempenha ação preventiva sobre a fermentação butírica.

\section{QUEIJOS ELABORADOS COM LEITE CRU E PASTEURIZADO}

Pelos diversos fatores mencionados anteriormente e pela própria tradição cultural encontram-se, nas mais diversas regiões do mundo, vários tipos de queijos elaborados com leite cru e pasteurizado (Tabela 4). 
TABELA 4-ALGUNS TIPOS DE QUEIJOS TRADICIONALMENTE ELABORADOS COM LEITE CRU E PASTEURIZADO

\begin{tabular}{l|l}
\hline Tipo de Queijo & Referência \\
\hline Leite cru & \\
Suiço & KRASHENININ et al. (36) \\
Parmesão ("Grana cheese") & ZAPPAROLI et al. (60) \\
Cebrero & QUINTO et al. (46) \\
Quartirolo di monte & PALEARI et al. (44) \\
Camembert & SCHMIDT \& LENOIR (48) \\
Herve & WAES (55) \\
Domiati & HOFI et al. (28) \\
Holandeses (duros) & MOSSEL (4l) \\
& \\
Leite Pasteurizado & \\
Cottage & DZUREC \& ZALL (18) \\
Mussarela & PETRACCA et al. (45) \\
Rossiiskii & KARLIKANOVA \& DUROVA (35) \\
Prato & FURTADO et al. (21) \\
\hline
\end{tabular}

\section{ASPECTOS LEGAIS}

Os Estados Unidos e o Canadá exigem em seus padrões a pasteurização do leite ou a cura dos queijos por, no mínimo, 60 dias a $2{ }^{\circ} \mathrm{C}(9,32)$. MOUSTAFA et al. (42) sugerem que a cura seja efetuada por no mínimo 90-120 dias para eliminação dos patógenos, afirmando que 60 dias é insuficiente. HEESCHEN (26) lembra que na revisão da legislação alemã (abril de 1986) ficou estabelecido que todo o leite utilizado para fabricação de queijo deve ser tratado termicamente.

No Brasil, os padrões variam de acordo com o produto, mas em geral é exigida a pasteurização ou a cura (8). A Tabela 5 lista alguns tipos de queijos e os requerimentos exigidos pelos orgãos fiscalizadores do Brasil e dos Estados Unidos.

A legislação brasileira (8) estabelece, como meios de verificação da eficácia da pasteurização, os testes de fosfatase (negativa), peroxidase (positiva), contagem aeróbica em placas (para o leite destinado a industrialização o número máximo permitido é $150.000 \mathrm{UFC} / \mathrm{mL}$, após a pasteurização) e coliformes (após a pasteurização o leite deve apresentarse isento de coliformes em $1 \mathrm{~mL}$ de amostra). 
TABELA 5 - ALGUNS TIPOS DE QUEIJOS ELABORADOS COM LEITE CRU E PASTEURIZADO CONFORME AUTORIZAÇÃO DOS ORGÃOS FISCALIZADORES DO BRASIL E DOS ESTADOS UNIDOS

\begin{tabular}{|c|c|c|}
\hline Tipo de Queijo & Pasteurização é requerida & Tempo de cura (mínimo) \\
\hline \multicolumn{3}{|l|}{ - BRASIL } \\
\hline Cheddar & $\operatorname{sim}$ & 90 dias \\
\hline Edam ou Reino & $\operatorname{sim}$ & 60 dias \\
\hline Emental & não & 4 meses \\
\hline Gorgonzola & não & 90 dias \\
\hline Gouda & $\operatorname{sim}$ & 20 dias \\
\hline Gruyère & não & 4 meses \\
\hline Minas padrão & $\operatorname{sim}$ & 20 dias \\
\hline Mussarela & $\operatorname{sim}$ & - \\
\hline Parmesão & não & 6 meses \\
\hline Prato & $\operatorname{sim}$ & 20 dias \\
\hline Provolone curado & não & 60 dias \\
\hline Roquefort & não & 90 dias \\
\hline Tilsit & $\operatorname{sim}$ & 30 dias \\
\hline \multicolumn{3}{|l|}{ - EUA } \\
\hline Blue & não & 60 dias \\
\hline Brick & não & 60 dias a $2{ }^{\circ} \mathrm{C}$ \\
\hline Cheddar & não & 60 dias a $2^{\circ} \mathrm{C}$ \\
\hline Colby & não & 60 dias a $2^{\circ} \mathrm{C}$ \\
\hline Cottage & $\operatorname{sim}$ & - \\
\hline Cream & $\operatorname{sim}$ & - \\
\hline Edam & não & 60 dias a $2{ }^{\circ} \mathrm{C}$ \\
\hline Gorgonzola & não & 90 dias \\
\hline Gouda & não & 60 dias a $2^{\circ} \mathrm{C}$ \\
\hline Gruyère & não & 90 dias \\
\hline Mussarela & $\operatorname{sim}$ & - \\
\hline Parmesão e Reggiano & não & 10 meses \\
\hline Provolone & não & 60 dias a $2{ }^{\circ} \mathrm{C}$ \\
\hline Roquefort & não & 60 dias \\
\hline Suíço & não & 60 dias \\
\hline
\end{tabular}

Fonte: BRASIL (8); JOHNSON et al. (32). 


\section{CONSIDERAÇÕES FINAIS}

O tratamento térmico do leite destinado para fabricação de queijo, sem dúvida, proporciona maior segurança. No caso específico do Brasil é necessário não só tratar o leite termicamente, mas exercer controle efetivo e sistemático desde a produção do leite até a comercialização dos queijos nos pontos de venda.

A legislação brasileira de queijos carece de revisão para ajustar certos padrões. Poderia ser permitido o uso da pasteurização com ejetor de vapor, cuja eficácia foi comprovada tecnicamente e que se mostra como opção viável para pequenas queijarias, que não deixariam de pasteurizar o leite, aumentando, assim, a segurança para o consumidor.

Para certos tipos de queijos como os da família Grana e o Suiço não deveria ser exigida pasteurização do leite, para não prejudicar seu sabor. Porém, o uso de matéria-prima de qualidade elevada, sua elaboração em condições higiênicas estritas e o respeito aos tempos de cura devidos, poderiam ser fiscalizados.

A produção de queijos no Brasil pode ser bastante melhorada, não só nos aspectos tecnológicos e de segurança do consumidor, mas também nos custos de produção e preços pagos aos produtores de leite e queijos.

\section{Abstract}

Milk for cheese manufacture is generally heat-treated. The pasteurization of milk for cheesemaking is not as widely accepted as the pasteurization of drinking milk. Some countries recommend pasteurization of all milk intended for cheesemaking. Different kinds of heat treatment of milk, technological factors affecting cheesemaking, legal regulations and exemples of traditional cheeses made from raw and pasteurized milk are reviewed.

\section{REFERÊNCIAS BIBLIOGRÁFICAS}

1 AAE, $O$. Pretreatment of cheese milk at the dairy: experience with regard to product quality. Meieriteknikk, Oslo, n. 2 (suplemento), p. 5-11, 1980.

2 AJZENTAL, Ari. Pasteurização do leite: eficiência do processo em função da carga microbiana inicial. São Paulo, 1990. 43 p. Tese (Mestrado em Epidemiologia Experimental e Aplicada a Zoonoses) - Departamento de Medicina Veterinária Preventiva e Saúde Animal, Faculdade de Medicina Veterinária e Zootecnia, Universidade de São Paulo. 
3 AJZENTAL, A. Os caminhos do leite: da ordenha ao consumidor.

Leite e Derivados, São Paulo, v. 18, n. 5; p. 29-40, set./out. 1994.

4 AURELI, P., FRANCIOSA, G., MANOCHEHR, P. Foodborne botulism in Italy. Lancet, London, v. 348, n. 9041, p. 1594, 1996.

5 BACHMANN, H. P., McNULTY, D. A., McSWEENEY, P.L.H., RÜEGG, $M$. Experimental designs for studying the influence of the raw milk flora on cheese characteristics: a review. Journal of the Society of Dairy Technology, London, v. 49, n. 2, p. 53-56, May 1996.

6 BANKS, J. M., GRIFFITHS, M. W., PHILLIPS, J. D., MUIR, D. D. The yield and quality of cheddar cheese produced from thermized milk. Dairy Industries International, London, v. 51, n. 7, p. 31, 32, 34, 35, July 1986.

7 BANKS, J. M., LAW, A.J.R., LEAVER, J., HORNE, D.S. Sensory and functional properties of cheese: incorporation of whey proteins by $\mathrm{pH}$ manipulation and heat treatment. Journal of the Society of Dairy Technology, London, v. 47, n. 4, p. 124-131, Oct./Dec. 1994.

8 BRASIL. Ministério da Agricultura. Regulamento da inspeção industrial e sanitária de produtos de origem animal. Brasília: Ministério da Agricultura, 1980. 166 p.

9 BRODSKY, M.H. A research note: evaluation of the bacteriological health risk of 60 day aged raw milk cheddar cheese. Journal of Food Protection, Ames, v. 47, n. 7, p. 530-531, 536, July 1984.

10 BRULE, G. Les mineraux du lait. Revue Laitiére Française, Paris, v. 400, p. $61-65,1981$.

11 BRYAN, F.L. Epidemiology of milk-borne diseases. Journal of Food Protection, Ames, v. 46, n. 7, p. 637-649, July 1983.

12 BUSANI, S.F.B., OLIVEIRA, J.S. de. Leite pasteurizado: sua qualidade desde a fonte de produção. Coletânea do ITAL, Campinas, v. 19, n. 2, p. 113-120, jul./dez. 1989.

13 CAMPBELL, D.M., COWDEN, J.M., MORRIS, G., REILLY, W.J., O'BRIEN, S.J. All milk products should be heat treated. British Medical Journal, London, v. 312, n. 7038, p. 1099, 1996.

14 COGHILL, D.M., MUTZELBURG, I.D., BIRCH, S.J. Effect of thermization on the bacteriological and chemical quality of milk. The Australian Journal of Dairy Technology, Highett, v. $37, n$. 2 , p. 48-50, June 1982. 
15 COMISSION DEL CODEX ALIMENTARIUS. Organización de las Naciones Unidas para la Agricultura e la Alimentacion. Organizacion Mundial de la Salud. Definiciones de tratamiento térmico segun se aplica a la leche y los productos lácteos. Roma : FAO/OMS, 1982.

16 D'AOUST, J.Y. Manufacture of dairy products from unpasteurized milk a safety assessment. Journal of Food Protection, Ames, v. 52, n 12, p. 906-914, Dec. 1989.

17 DZUREC, D.J., ZALL, R. R. Effect of on farm heating and storage of milk on Cottage cheese yield. Journal of Dairy Science, Champaign, v. 65, n. 12, p. 2296-2300, Dec. 1982

18 DZUREC, D.J., ZALL, R.R. On farm heating of milk increases Cottage cheese yields. Cultured Dairy Products Journal, Washington, v. 21, n. 1, p. 25-26, Jan./Mar. 1986.

19 EYLES, M. Raw milk cheese: the issues. The Australian Journal of Dairy Technology, Highett, v. 47, n. 2, p. 102-105, Nov. 1992.

20 FOX, P.F., MORRISSEY, P.A. Reviews of the progress of dairy science: the heat stability of milk. Journal Dairy Research, Cambrigde, v. 44, n. 3, p. 627-646, July/Set. 1977.

21 FURTADO, M. M., WOLFSCHOON-POMBO, A.F., VENTURA, R. F. Pasteurização do leite por ejetor de vapor: considerações sobre diluição do leite e rendimento da fabricação de queijo Prato. Revista do ILCT, Juiz de Fora, v. 43, n. 256, p. 3-9, mar./abr. 1988.

22 FURTADO, M.M. A arte e a ciência do queijo. 2.ed. São Paulo : Globo, 1990. 297 p.

23 GALLMANN, P., PUHAN, Z. Quality of Raclette cheeses made from pasteurized or raw milk. Lebensmittel Wissenschaft und Technologie, London/Zurich, v. 16, n. 2, p. 96-102, März/Apr. 1983

24 GLAESER, $H$. Does milk pasteurization have a negative influence on cheese quality?. DMZ - Lebensmittel industrie und Milchwirtschaft, Muchen, v. 113, n. 44, p. 1361-1367, 1992.

25 HADLAND, G. Testing farm milk for spores: thermization/ripening of cooled milk. Meieriposten, Oslo, v. 71, n. 3, p. 13-17, 1982. 
26 HEESCHEN, $W$. Dangers to health from cheese made from raw milk. Deutsche Milchwirtschaft, Leipzig, v. 39, n. 5, p. 145-149, 1988.

27 HESKESTAD, R. Thermization of milk prior to curd formation. Meieriposten, Oslo, v. 74, n. 3, p. 66-68, 1985.

$28 \mathrm{HOFI}$, A. A., EL-SHIBINY,S., MAHRAN, G. A., FARAHAT, S. M., ABDEL-BAKY, A. A. Changes in the flavour components of soft cheese as affected by milk source and heat treatment. Egyptian Journal of Dairy Science, Cairo, v. 3, n. 1, p. 1-5, Jan./June 1975.

29 HONER, C. Cheese changes. Dairy Field, Birmingham, v. 177, n. 10 , p. 56 , Oct. 1994

30 HONER, C. Rethinking heat. Dairy Field, Birmingham, v. 177 , n. 10 , p. $25-27$, Oct. 1994.

31 JENSEN, P. S. Research on cheesemaking using high temperature pasteurization of milk. Maelkeritidende, Odense, v. 102, n. 16, p. 356-358, 1989

32 JOHNSON, E. A., NELSON, J. H., JOHNSON, M. Microbiological safety of cheese made from heat-treated milk, Part I. Executive summary, introduction and history. Journal of Food Protection, Ames, v. 53, n. 5, p. 441-452, May 1990.

33 JOHNSON, E. A., NELSON, J. H., JOHNSON, M. Microbiological safety of cheese made from heat-treated milk, Part II. Microbiology. Journal of Food Protection, Ames, v. 53, n. 6, p. 519-540, June
1990.

34 JOHNSON, E. A., NELSON, J. H., JOHNSON, M. Microbiological safety of cheese made from heat-treated milk, Part III. Technology, discussion, recommendations, bibliografy. Journal of Food Protection, Ames, v. 53, n. 7, p. 610-623, July 1990.

35 KARLIKANOVA, S. N., DUROVA, E. I. Use of double heat treatment of milk in cheesemaking. Trudy, Vsesoyuznyi Nauchno issledovatel' skii Institut Maslodel'noi i Syrodel noi Promyshlennosti, Moscow, n. 29, p. 10-15, 1979.

36 KRASHENININ, P. F., ZHARENOV, D. A., YAKHONTOV, P. D. Manufacture of Swiss cheese in blocks. Molochnaya Promyshlennost', Moscow, n. 1, p. 5-6, 1979.

37 KRISTOFFERSEN, T. Development of flavor in cheese. Milchwissenschaft, Munich, v. 40, n. 4, p. 197-199, Apr. 1985. 
38 KWON, H.Y., LEE, B.O., KWON, Y.J. Factor to increase the yield of cheese. Korean Journal of Dairy Science, Suwon, v. 11, n. 4, p. 232-234, Oct./Dec. 1989.

39 MARSHALL, R.J. Increasing cheese yields by high heat treatment of milk. Journal of Dairy Research, Cambrigde, v. 53, n. 2, p. 313322, Apr./Jun. 1986.

40 MORR, C. V. Effect of HTST pasteurization of milk, cheese whey, and cheese whey UF retentate upon the composition, physicochemical and functional properties of whey protein concentrates. Journal of Food Science, Chicago, v. 52, n. 2, p. 312-317, Mar./Apr. 1987.

41 MOSSEL, D.A.A. Cheese made from raw milk: a comment from Europe. Journal of Infectious Diseases, Chicago, v. 148, n. 6, p. 1169-1170, Jun. 1983.

42 MOUSTAFA, M.K., AHMED, A.A.H., MARTH, E.H. Behaviour of virulent Yersinia enterocolitica during manufacture and storage of Colby like cheese. Journal of Food Protection, Ames, v. 46, n. 4, p. 318-320, Apr. 1983.

43 MUIR, D.D. The shelf-life of dairy products. I. Factors influencing raw milk and fresh products. Journal of the Society of Dairy Technology, London, v. 49, n. 1, p. 24-32, Feb. 1996.

44 PALEARI, M. A., SONCINI, G., BERETTA, G., DRAGONI, I., PIANTONI, L. A study on a typical mountain raw milk cheese. Sciences des Aliments, Cachan Cedex, v. 13, n. 4, p. 723-735, July/Ago. 1993.

45 PETRACCA, G., PROCHOWSKI, D., MARTINO, M., MAZZEO, A., PETRUNTI, M.F., RICCIO, M.D., VISCARA, D. Controllo igienico sanitario della muzzarelle molisane. IL Latte, Milano, v. 8, n. 4, p. 522-524, lugl./ago. 1983.

46 QUINTO, E., FRANCO, C., RODRIGUEZ-OTERO, J.L., FENTE, C., CEPEDA, A. Microbiological quality of Cebrero cheese from northwest Spain. Journal of Food Safety, Westport, v. 14, n. 1, p. 1-8, Jan./Mar. 1994.

47 RAMAZANOV, I. U. Factor improving the quality of pickled cheeses. Molochnaya Promyshlennost', Moscow, n. 1, p. 15-17, 1985.

48 SCHMIDT, J.L., LENOIR, J. Study of the yeast flora of Cammembert cheese: changes during ripening. Le Lait, Paris, v. 58, n. 577, p. 355-370, 1978. 
49 SWART, G. J., DOWNES, T.E.H., MERWE, N.L. van der, GIBHARD, $H$. M. The effect of thermization on yield and quality of cheddar cheese. Suid Afrikaanse Tydskrif vir Suiwelkunde, Pretoria, v. 19, n. 3, p. 91-98, July/Sept. 1987.

50 USTUNOL, Z., BROWN, R.J. Effects of heat treatment and post treatment holding time on rennet clotting of milk. Journal of Dairy Science, Champaign, v. 68, n. 3, 526-530, Mar. 1985.

51 VALLE, J.L.E. do, CONTIERO, J. Efeitos do processamento térmico sobre as proteínas do leite. Boletim do ITAL, Campinas, v. 18, n. 4, p. 449-468, out./dez. 1981.

52 VENTURA, R. F., RUSIG, O. Ejetor de vapor: sistema de pasteurização de leite destinado à fabricação de queijos ( $1^{\mathrm{a}}$. parte) Revista do ILCT, Juiz de Fora, v. 38, n. 226, p. 3-16, mar./abr. 1983.

53 VENTURA, R. F., RUSIG, O. Ejetor de vapor: sistema de pasteurização de leite destinado à fabricação de queijos ( $7^{\mathrm{a}}$. parte) Revista do ILCT, Juiz de Fora, v. 39, n. 234, p. 31-35, jul./ago. 1984.

54 VENTURA, R. F., FURTADO, M. M., WOLFSCHOON-POMBO, A. F., LOURENÇO NETO, J. P. de M., LIMA, A. de. Queijo prato: comparação de fabricação usando leite pasteurizado por sistema de placas e ejetor de vapor (nota prévia). Revista do ILCT, Juiz de Fora, v. 39, n. 235, p. 59-70, set./out. 1984.

55 WAES, G. Coagulase positive Staphylococci in Herve cheese. Revue de l'Agriculture, Brussels, v. 30, n. 3, p. 617-628, May/June 1977.

56 WILSTER, G. H. Practical cheesemaking. 10.ed. Corvallis : O.S.U. Book Stores, Inc., 1964. [50] p.

57 WOLFSCHOON-POMBO, A. F., FURTADO, M. M. Uma tecnologia a ser preservada: o queijo prato na região sul de Minas Gerais. Revista Brasileira de Tecnologia, v. 14, n. 5/6, p. 50-54, set./dez. 1983.

58 YETISMEYEN, A., OSMANLIOGLU, M.A., KAPTAN, B. A study on effects of different heat-treatments on curd and whey quality in white pickled cheese. Gida, Ankara, v. 20, n. 6, p. 371-382, 1995.

59 ZALAZAR, C. A., MEINARDI, C.A., BERNAL DE ZALAZAR, S., CANDIOTI, M. The effect of previous heat treatment on the keeping quality of raw milk during cold storage. Microbiologie, Aliments, Nutrition, Chatenay-Malabry, v. 6, n. 4, p. 373-378, Oct./Dec. 1988. 
60 ZAPPAROLI, G. A., ALBERTINI, B., FANTUZZI, U., FAGNONI, P., ANNIBALDI, S. Effects of microbiological quality of milk on the qualify of Grana cheese. IL Latte, Milano, v. 12, n. 9, p. 812-815, Sep. 1987 